\title{
Publisher's Note: Role of adiabaticity in controlling alkali-metal fine-structure mixing induced by rare gases [Phys. Rev. A 95, 042708 (2017)]
}

\author{
Ben Eshel, Joseph A. Cardoza, David E. Weeks, and Glen P. Perram \\ (Received 3 May 2017; published 10 May 2017)
}

DOI: 10.1103/PhysRevA.95.059905

This paper was published online on 20 April 2017 with errors in Eqs. (2), (3), (8), and (17), a spacing error on page 1, and a misformatting on page 4 . On page 1 , left-hand column, there is a space missing between $D_{2}$ and ${ }^{2} S_{1 / 2}$. On page 4 , left-hand column, 4 lines below Eq. (8) should read as "correlating with the first excited ${ }^{2} P$ states. ..." In Eq. (17) the term $\left(k T^{3 / 2} / \mu\right)$ which should read as $(k T / \mu)^{1 / 2}$." In Eqs. (2), (3), and (8), the term $n^{*}$ was set inconsistently. All $n$ values should read $n^{*}$ in these equations. The equations, typography, and spacing errors have been corrected as of 27 April 2017. The equations, typography, and spacing errors are correct in the printed version of the journal. 